NASA Technical Memorandum 100486

\title{
MODIFICATION TO THE LANGLEY 8-FOOT HIGH TEMPERATURE TUNNEL FOR HYPERSONIC PROPULSION TESTING
}

D. E. REUBUSH, R. L. PUSTER, H. N. KELLY

\author{
(NASA-TH-100486) HODIFICATIC TC THE \\ $\$ 87-27957$ \\ IANGIEY 8-FOOT HIGE TEBPERATOEE IUNAEL FOR \\ LYEEBSCNIC PECEOLSICA TESTIAG (WASA) $13 \mathrm{p}$ \\ Avail: HTIS EC AC2/HE AO1 CSCL 2OD \\ Unclas \\ G3/34 0094125
}

JUNE 1987

4

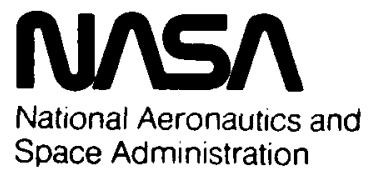

Langley Research Center

Hampton, Virginia 23665 
MODIFICATION TO THE LANGLEY 8-FOOT HIGH TEMPERATURE TUNNEL FOR HYPERSONIC PROPULSION TESTING

\author{
David E. Reubush* \\ Richard L. Puster $\star *$ \\ NASA, Langley Research Center \\ H. Neale Kelly* \\ PRC Kentron
}

\section{ABSTRACT}

This paper describes the modifications currently underway to the Langley 8-foot High Temperature Tunnel to produce a new, unique national resource for testing of hypersonic air-breathing propulsion systems. The current tunne 1, which has been used for aerothermal loads and structures research since its inception, is being modified with the addition of a LOX system to bring the oxygen content of the test medium up to that of air, the addition of alternate Mach number capability (4 and 5) to augment the current $M=7$ capability, improvements to the tunne 1 hardware to reduce maintenance downtime, the addition of a hydrogen system to allow the testing of hydrogen powered engines, and a new data system to increase both the quantity and quality of the data obtained. The paper discusses both the modifications and the deve lopment thereof.

\section{INTRODUCTION}

In the past several years there has been a resurgent interest in hypersonics. This is particularly evidenced by the National Aerospace Plane program (NASP see ref. 1). In order to meet the goal of the NASP program of developing the technology to enable the construction of an aerospace vehicle which will be able to take off horizontally and reach orbit significant research must be conducted to develop and validate this technology. One of the most important areas of research for development of the NASP and an upcoming generation of high speed air-breathing vehicles will be that of developing and refining the propulsion system and its integration into the vehicle. In order to conduct this research there must be facilities available with capabilities to adequately simulate the proper flight environments across the speed range the vehicles will encounter from low subsonic through high hypersonic. In order to meet the need for propulsion testing in the high supersonic - low hypersonic area $(M=$ 4 to 7$)$ for the NASP, other hypersonic aircraft, and hypersonic air-breathing missiles, NASA has underway the

* Aerospace Technologist, Aerothermal Loads Branch, LAD, Member AIAA

**Aerospace Technologist, Aerothermal Loads Branch, LAD, NonMember AIAA

**Aerospace Technologist, PRC Kentron, NonMember AIAA modification of the Langley 8-Foot High Temperature Tunnel to add alternate Mach number capability and add oxygen enrichment to allow the testing of operating engines at these Mach numbers and at true temperature levels. This paper will describe the tunnel, the modifications being made to it, and discuss the development work necessary to ensure the modifications will be successful. (This paper provides updated and expanded information from that reported in ref. 2.)

\section{DISCUSSION}

Current Status of 8-Foot High Temperature Tunnel

A schematic of the Langley 8-Foot High Temperature Tunnel as it exists today is shown in figure 1. The tunnel was designed in the late $1950^{\prime}$ 's and came into service in the middle 1960 's as a facility to conduct research in the areas of aerothermal loads and aerothermostructures and has been primarily used as such for the 1ast 20 years. The tunnel is of the blow-down type and uses the combustion products of methane and air as a test medium. The combustion of high pressure methane enables the tunnel to simulate the high flow energy levels and true temperature of flight at its nominal Mach number of 7 . Actual Mach number varies from about 5.8 to 7.3 depending on total temperature and pressure. This variation in Mach number is due to the fact that the flow in the nozzle is non-isentropic. That is, there are rea? $g$ as effects and some of the water from the combustion process condenses in the products of combustion test medium. Recent unpublished calculations by Erickson of Langley indicate that the condensation occurs about $19 \mathrm{ft}$. from the throat and that the resulting water droplets are about 1 micron in diameter. Condensation is greatest at low temperatures and high pressures and essentially disappears at high temperatures and low pressures. The tunnel test section total pressure can be varied from about 150 psia up to 2400 psia while total temperature can be varied from about $2400^{\circ} R$ to about 3600 ${ }^{\circ}$. These variations yield a Reynolds number range from about $0.3 \mathrm{million}$ per foot to 2.2 million per foot, dynamic pressures from about 250 psf to about 1800 psf, and simulated altitude from about $80,000 \mathrm{ft}$. to about $130,000 \mathrm{ft}$. Locally stored air, about $0.4 \mathrm{million}$ pounds (stored in a bottle field of 14,700 cuft. at $6,000 \mathrm{psi}$ ), is sufficient to run the 
tunnel and power the downstream $M=3.5 \mathrm{air}$ ejector (which has the capability of dropping the test chamber pressure to 0.09 psia) for run times ranging from $30 \mathrm{sec}$. to over 2 minutes depending on the desired test conditions (which will vary the total amount of flow required by both the tunnel and ejector). The con $i c a l /$ contoured $M=7$ nozzle is $51.5 \mathrm{ft}$. in length and extends into a $26 \mathrm{ft}$. diameter test chamber which houses the $8 \mathrm{ft}$. diameter, $12 \mathrm{ft}$. long open jet test section. Since the methane-air combustion necessary for production of the high enthalpy levels for realistic flight simulation depletes the air of oxygen, the tunnel as it currently exists cannot be used for engine testing (the test medium cannot support further combustion). This is the motivation for the oxygen enrichment portion of the modification project, which will be discussed later.

In order to facilitate starting the tunnel and to protect models from start-up and shut-down dynamic loads, mode ls under test are stored beneath the test section and inserted into the stream after steady-state hypersonic flow has been established. A hydraulic elevator system is used to insert the model into the test section from its storage position in as little as 1 second, subjecting the model to an acce leration of at most $2 \mathrm{~g} \cdot s$. Figure 2 is a triple exposure of a model being inserted into the test section. The carriage, on which the model rides, weighs approximately 15 tons. Two interchangeable carriages are available: a pitch carriage (shown) on which the models are sting mounted from a curved strut with a capability of a $+/-20^{\circ}$ angle of attack variation and a yaw carriage on which the mode is are mounted on a turntable flush with the floor and can be rotated through a $+/-20^{\circ}$ yaw variation. The carriages can accomodate models weighing up to about 10,000 los.

Also visible in the upper right corner of figure 2 is a flow survey rake which resembles a large windshield wiper. The rake, which is pneumatically operated, can accomodate up to 37 interchangeable probes (i.e. temperature, pressure, gas sampling, heat flux) and can provide a flow field survey at any preselected longitudinal position in the test section either immediately prior to model insertion or immediately after model removal.

In addition to the capability of injecting a "cold" model into the hot stream (cold wall condition), the tunnel has a radiant preheating apparatus which can be used to preheat the model while it resides below the test section to simulate conditions where the vehicle has been in flight at high Mach numbers for a period of time (hot wall condition). Figure 3 shows a schematic and photographs of the preheating apparatus.

While primarily used for thermal loads and thermal protection system research, the facility has been used in the past for propulsion structures related research. In the late 1960's and early 1970's a full scale, flight weight, hydrogen cooled structural assembly model (SAM) of the hypersonic research engine (HRE) was tested as shown in figure 4 (ref. 3 ). This mode 1 was approximately $7.5 \mathrm{ft}$. long with a cow 1 in let diameter of $18 \mathrm{in}$. and a maximum diameter of $25 \mathrm{in}$. The mode 1, which featured an intricate hydrogen cooling system, was exposed to a total of approximately $30 \mathrm{~min}$. of hypersonic flight environment and 55 thermal cycles. It would have been desireable to investigate engine operation during this time period, however, as mentioned before, the oxygen deficient test medium precluded further combustion. To properly test hypersonic aircraft engines and a foreseen generation of high speed air-breathing missiles, the oxygen deficit in the test gas must be alleviated. This is the impetus for the oxygen enrichment portion of the modification project.

\section{Propulsion System Test Needs and Capabilities.}

An approximate Mach number-altitude corridor for air breathing engines is indicated in figure 5. The upper altitude limit on the corridor is established by the ability to sustain combustion while the lower altitude limit is established by the ability of the structures to withstand the loads resulting from the high temperatures and pressures generated at low altitudes. In the lower left corner of the figure are indicated the operational envelopes of the two large scale propulsion test facilities (Aero Propulsion Test Unit and Aero Propulsion System Test Facility) at the Air Force Arnold Engineering Development Center (AEDC). These two facilities provide propulsion system testing capability below a Mach number of about 4.5. However, for Mach numbers greater than this there is a definite need for additional test capability. The large cross-hatched block in the center of the figure indicates the test range for the 8-Foot $\mathrm{High}$ Temperature Tunnel with its current Mach number capability. This capability covers the $M=$ 6 to 7 range very well. However, there is still a need to fill in the test coverage between the AEOC facilities and the $8^{\prime}$ HTT. To fill in this gap the 8-Foot High Temperature Tunnel modification project will add the capability to test at alternate Mach numbers (4 and 5). These test capabilities are shown by the two thin blocks in the center of the figure. With the AEDC facilities and the $8^{\prime}$ HTT there will exist facilities capable of testing air-breathing hypersonic propulsion systems from take off up through $M=7$. It must be noted that the full $8^{\prime}$ HTT test capability will not be available with oxygen enrichment. The tunnel can operate at combustor total pressures up to about 4000 psia, but the run tank to be used in the liquid oxygen system is surplus Air Force Rocket Propulsion Laboratory equipment (to save money) and can only be used up to about 2300 psia. This will yield a reduced 
low altitude simulation capability as shown by the dashed line on figure 5 .

Use of Oxygen Enriched Combustion Products as a Test Medium.

Perhaps the greatest concern when considering the use of a facility, which utilizes combustion to produce the necessary high enthalpy levels required for true flight simulation, is that the products of combustion test medium (even when oxygen enriched) will not yield results applicable to flight in air. This is particularly true when engine operation is under study since there will be effects of the additional chemical species from the combustion process used to heat the test medium on the burning in the test engine. The suitability of using products of combustion as a test medium for research not involving engine operation (with particular regard to the $8^{\prime}$ HTT) was investigated in considerable detail and reported in reference 4 . The conclusion from that investigation was that the most important consideration in using products of combustion as a test medium was the condensation of water vapor. The condensation of water vapor can have a significant effect on the test section flow parameters, particularly if the temperature is low enough. However, if the test stream conditionis are measured in the test section and proper values of the thermodynamic and transport properties of the combustion are used in the data reduction good correlation can be obtained both with theory and with experimental results measured in air. The possible effects on the simulation of hydrogen-air combustion in an oxygen enriched products of combustion test medium (vitiated air) have been examined by use of theoretica) techniques (ref. 5 and 6). These studies indicate that the nitrous oxide species in the test medium will tend to reduce hydrogen ignition time when static temperatures are less than about $1980{ }^{\circ} R$ and have an insignificant effect above this temperature. The effect of water in the test gas is essentially opposite to that of the nitrous oxide, that is, be low about $1980^{\circ} \mathrm{R}$ water will retard hydrogen ignition while above $1980^{\circ} R$ its presence will decrease ignition time slightly. The combined effects of all the various species on predicted hydrogen reaction time is shown in figure 6 . As can be seen, the overall effect is small. The studies also addressed the effects of the flow contaminants on such things as flame stability (residence time). Reference 6 found that for vitiated air the flames are more stable for all mixtures with a maximum increase of about 14 percent. However, the general conclusion from reference 6 was "From the standpoint of designing practical supersonic combustors, the effect of facility contaminants on ignition time and flame stability are not a major concern."
Description of Tunnel Modifications and Development Thereof

A photograph of a scale model of the 8-Foot High Temperature Tunnel is shown in figure 7. Identified in this figure are the major components of the tunnel. These components will be described and their development discussed in the following figures starting with the combustor (center-right of the figure) and proceeding in the general direction of the flow.

Combustor, LOX, and fuel systems. - A cross-sectional drawing of the combustor in which the hot test gas is generated and in which the oxygen will be added is shown in figure 8. High pressure air from the 6000 psi storage field is introduced through a torus at the upstream end of the combustor. To protect the carbon steel combustor pressure vesse 1 from the hot combustion gases the air flows to the downstream end of the combustor in the annular space between the pressure vessel and an outer stainless steel liner where it turns $180^{\circ}$ and flows back upstream in the annular space between the outer liner and an inner nickel liner to approximately the mid point of the combustor. At this point the inner liner terminates and the air is dumped into the 3-foot diameter central portion of the combustor. Also, this point is the proposed location for the LOX spray apparatus (see figure).

The LOX system is designed with a 28,000 gal. low pressure storage tank and an 8,000 gal. run tank capable of delivering $150 \mathrm{lbs} . / \mathrm{sec}$. for a maximum run time of 3 minutes. As mentioned previously, the run tank was obtained as surplus equipment from the Air Force Rocket Propulsion Laboatory. Although the surplus tank results in a considerable cost saving, the 2300 psi pressure rating of the tank is not as high as desired. Because of this pressure limitation, the facility operating with oxygen enrichment will be limited to a maximum dynamic pressure of about 1800 psf or minimum simulated altitudes of approximate ly $60,000 \mathrm{ft}$. at $M=4,70,000$ $\mathrm{ft}$. at $M=5$, and $90,000 \mathrm{ft}$. at $M=7$. To provide for future growth all the piping and valving will be designed for 5000 psi operation.

To provide first-hand experience in handling oxygen and to develop operationa procedures a mock-up of a previouly proposed LOX injection system was installed in the Langley 7" HTT which is the pilot facility for the $8^{\prime}$ HTT. This investigation provided valuable experience in handling cryogenic fluids. It also showed that the injection of oxygen did not introduce any large transients, in fact, much of the noise introduced into the flow by the combustor was attenuated (a reduction of from $30-40 \%$ ). The attenuation was due to a significant increase in the efficiency of methane combustion. However, 
the resulting nigher temperature operation coupled with an apparent upstream movement of the flame front overheated the fuel spray bar. This problem was overcome in the pilot facility by slightly increasing the fuel pressure and by using an all welded Inconel 625 injector. It is anticipated that similar "fine tuning" will be required in the full scale facility. The development of the control system for the LOX injection was a research project unto itse If and has been documented in ref. 7 .

After the oxygen is sprayed into the air the gases mix ( $f$ lowing downstream at about $30 \mathrm{ft} . / \mathrm{sec}$.) for a proposed distance of about $2.5 \mathrm{ft}$. at which point the air-oxygen mixture reaches the fuel spray bar where the methane fuel is introduced. The fuel spray bar is a series of tubes formed into concentric circles with a pattern of spray holes derived experimentally to produce a uniform temperature distribution in the test section. The methane is supplied through two large pipes which extend from the upstream end of the combustor to the spray bar. (It was also found during the oxygen injection studies in the pilot facility that revising the methane fuel control system and air control system could further quiet the combustor generated noise of the facility. The previous control systems tended tc rause the control valves to oscillate slightly which resulted in oscillations in the combusting flow and thus noise.)

Combustion occurs in the downstream na If of the combustor and the not gases then flow through a convergent divergent, conical/contoured nozzle into the test section. At present the convergent section of the nozzle is water cooled and the nozzle throat, which experiences the most severe environment, is $f i l m$ cooled using an annular film of air introduced just upstream of the throat. This film cooling air is injected at the point in the subsonic contraction where the Mach number has reached 0.11 and amounts to from 20 to $30 \%$ of the total nozzle flow. This large quantity of cooling flow results in a relatively cool test section boundary layer with a test core of on ly about $4 \mathrm{ft}$. in diameter which has constant properties. In addition to the undesireable reduction in test section cross section with good flow properties the water and film cooled components have been the source of continuing trouble and will be replaced as part of the modifications.

Transpiration Cooled Approach Section and Throat. - A sketch of the proposed new approach section and nozzle is shown in figure 9. This section; which has a maximum internal diameter of 36 in., a minimum throat diameter of 5.6 in., and is approximately $7.2 \mathrm{ft}$. long; is being fabricated by Aerojet Tech Systems using a plate let concept, which they pioneered for controlling the distribution of the transpiration fluid (in this case air)(ref. 8). In this concept, hydraulic passages are photoetched on thin sheets (platelets). The platelets vary in thickness and are bonded together in sections with the injection slot size and mass flow proportional to the local heat

flux. The design technique involves calculating the surface conditions and gas chemistry, then determining the wall heat transfer rate, and lastly calculating the transpiration coolant flow to maintain the wall at the desired temperature. The design mass flow for the transpiration cooled approach section and nozzle throat is about half of that currently used for just film cooling the throat. This reduced flow rate will be reflected in an increase in the hot gas flowing through the nozzle, a reduction in condensation losses, a larger region of uniform temperature in the test section, and an increase in run time. The actual quantity of transpiration cooling air flow will have to be determined experimentally, however, it has been calculated that up to 3 times the theoretical design value could be injected before the throat boundary layer would be blown off the surface.

Alternate Mach Number Capability.- Test conditions in the unmodified 8 HT are at the lower end of the scramjet range (fig. 5). However, for Mach numbers in the range for ram jet testing and, in particular, the critical turbojet to ramjet transition range, the nozzle must be reconfigured. To obtain the desired Mach numbers, provide the high dynamic pressures required, and reduce cost by utilizing the maximum portion of existing equipment possible; a dual throat - mixer concept similar to that used to convert Tunnel " $C$ " at the AEDC Von Karman Gas Dynamics Facility from a Mach 10 to a Mach 4 true temperature tunnel was selected (ref. 9). This concept has also been used to provide increased capabilities for the Langley Scramjet Test Facility (ref. 10). For the 8' HTT application, as illustrated by figure 10 , a section of the existing nozzle will be removed and a mixer with interchangeable nozzle sections will be installed. The interchangeable, $M=4$ and 5 , nozzle sections will consist of two parts, a nozzle throat insert and a downstream section that nrovides a transition from the insert to the last 18.4 $\mathrm{ft}$. of the downstream end of the existing $M$ $=7$ nozzle which will not be replaced. The replaceable section of the $M=7$ nozzle and the mixer/alternate Mach number nozzle will ride on air bearings to facilitate Mach number change capability.

Mixer Development.- The purpose of the mixer is to increase the total mass flow and to reduce the temperature by adding ambient temperature air to the hot, gas flowing from the existing combustor so as to obtain true temperature simulation and obtain high dynamic pressures at the lower Mach numbers. The mixer approach was selected in lieu of enlarging the existing 
throat. If a larger throat would have been used it would have been more difficult to maintain combustion in the combustor due to the increased flow velocity necessary to pass the increased mass flow for the lower Mach number conditions. In addition, the mixer approach facilitates changing Mach numbers since the alternate Mach number nozzles now do not have to be cooled. (The mixed flow for the lower Mach numbers is sufficiently cool to allow use of a heat sink design for the alternate Mach number nozzle throats.) There was initally a concern that it would be necessary to utilize mechanical means (such as the perforated metal plates and screens used at AEDC - ref. 11) to ensure adequate mixing. However, an aerodynamic concept had been successfully used at the Langley Mach 7 Scramjet Test Facility (ref. 10), and it was decided to investigate this type of concept, since the conditions in the 8-Foot mixer would be too severe for uncooled plates or screens. Tests were conducted in the 7" HTT pilot facility to investigate mixing concepts.

Figure 11 details the successful mixer design for the pilot tunnel. In this concept, the hot flow was expanded through the $M=7$ nozzle to a Mach number of 3.05 at which point tangential injectors were located, which injected equal Mach number air into the boundary layer to energize it. A series of normal sonic injectors were then located slightly downstream of the tangential injectors and the injection of air through these normal injectors initiated the supersonic diffusion of the hot $M=3$ gas (the previous tangentia) injectors prevented the normal injection from separating the boundary layer.). The process was then repeated with the second set of tangential injectors having a Mach number of 2.25. At the end of the conical diffuser the flow encountered a relatively large amount of air injected in the upstream direction $\left(-115^{\circ}\right.$ fig. 12) followed by additional normal injection at the break point in a sudden expansion diffuser. The slowed and mixing flow then entered the mixing chamber where final mixing took place. The upstream injected air served to cancel the existing momentum of the hot, partially mixed gas and enabled the set of normal injectors to complete the diffusion and set up a series of backward flowing vortices that also allowed the flow to reattach to the walls of the mixer. Additional cooling air was injected in the main body of the mixing chamber to cool the mixing chamber liner. The proportion of the cooling air injected through the various injectors was varied slightly depending on whether the $M=4$ or $M=5$ nozzles were installed at the downstream end of the mixing chamber. The success of the mixer design can be seen in figure 13, which shows the total temperature profiles measured in the mixer and test section of the pilot tunnel at both $M=4$ and 5 . The resulting design for the $8^{\prime}$ HTT with a tabulation of the proposed flow rates is shown in figure 14. The only significant difference, between the design for the full scale tunnel and that developed for the pilot tunnel, is that the full scale tunnel will have an additional set of tangential and normal injectors in the supersonic diffuser.

Nozzle Design Process. - The requirement that as much of the existing tunnel structure as possible be utilized in the modified facility resulted in the requirement that the new alternate Mach number nozzles interface with about 18.4 $\mathrm{ft}$. of the downstream end of the existing $M$ $=7$ nozzle. In addition, it was desired that for the central $60 \%$ of the nozzle exit plane the maximum Mach number variation would be no more than 0.2 while the maximum variation in static temperature be $100^{\circ} \mathrm{F}$. These rather stringent requirements led to a new nozzle design technique for the $M=4$ and 5 alternate nozzles. That is, since the desired Mach number, required length, and nozzle exit geometry were fixed, a reverse calculation procedure was developed to essentially "work backwards" to obtain the nozzle contour to fit within the required constraints. This procedure involved interactions between and iterations of a method of characteristics code with real gas effects accounted for, a boundary layer code with capability to account for real gas effects and wall mass injection, and an Euler code with capability to account for equilibrium chemistry effects. The resulting nozzle contours were then checked with a Navier-Stokes code. Details of this design process can be found in ref. 12. Predicted exit plane Mach number distributions for the $M=4$ and 5 nozzles are shown in figure 15. As can be seen, the Mach number distributions are well within the desired variation.

For the $M=7$ nozzle the design requirements were even more stringent than for the $M=4$ and 5 nozzles, that is, only the new, transpiration cooled throat section involving a portion of the subsonic approach, the throat, and a small part of the supersonic expansion section could be changed. (This new section is approximately 86 in. long.) As a result, only the Navier-Stokes code with the capability for mass addition to simulate the transpiration cooling and reaction rate chemistry was used to iterate to a final design. This code is a three-dimensional extension of the code documented in ref. 13 and 14. An exit plane Mach number profile is also shown in figure 15. Again, the predicted distribution is quite good.

Operational Boundaries. - During mixer development work in the $7^{\prime \prime}$ HT $\mathrm{pilot}$ facility it was found that the tunnel would not start at the alternate Mach numbers using the standard starting procedure. From studying high speed shadowgraphs of the start it was observed that the diffuser could not capture the starting Mach disc which then grew in diameter with time in 
the test section. This phenomenon yielded two effects which combined to preclude the flow from starting. That is, the Mach disc produced a very large pressure loss which lowered the compression ratio available for starting and, since the Mach disc grew in diameter with time, the mass flow passing through the Mach disc also grew with time (the mass flow was increasing from zero toward the steady-state run amount which is significantly greater for the alternate Mach numbers than for the tunnel's design Mach number of 7) which further burdened the already choked mixing tube. The solution to this problem involved either an impulse type of start to force the starting shock across the open jet test section and into the diffuser (not practical for the $8^{\prime}$ HTT because of the large valves involved) or a minor modification to the entrance to the mixing tube lincreasing the diffuser entrance angle from 8.5 deg. to 11.7 deg.) to allow it to capture the starting shock when the Mach disc was still relatively small and to limit the ejector and mixer starting pressures to the ranges shown on figures 16 and 17 for the two alternate Mach numbers. Once the tunnel started the operating envelope could be expanded to the unstart limits shown on the figures. Similar starting and running erive lopes are expected for the 8-Foot at the alternate Mach numbers.

\section{Use of the Modified 8-Foot HIT for Propulsion Testing}

Mode 1s. - The large, approximately 8 $\mathrm{ft}$. diameter by over $12 \mathrm{ft}$. long, open jet test section will allow the testing of large models with operating engines over significant angle of attack and sideslip ranges. A typical, large scale model of an air-breathing missile is shown in figure 18 to illustrate now configurations, which utilize the forebody as part of the in let compression system, can be tested in large enough sca ie to evaluate component interactions with an operating engine. For large configurations, the test section size, while not allowing the testing of a full configuration mode 1 with engines operating at a large scale, will allow the investigation of the potentially critical interactions between multiple engine modules at angles of attack and yaw (particularly important in the event of an inlet unstart); the effects of engine scale on performance; and the performance of the afterbody as a nozzle expansion surface. In addition, the tunnel will provide the capability to evaluate the, generally unscalable, thermal/structural performance of the flight weight, fuel cooled engine structures at essentially full size. A multiple scramjet engine module concept is shown installed in the tunnel in the sketch of figure 19.

Utilities. - The various utilities, which are available in the test chamber of the $8^{\prime} H T T$, are listed in fig. 20 . The electrical power (up to $1.6 \mathrm{Mw}$ ) can be divided into 15 separately contollable zones of from 0 to 440 volts $A C$. Ambient temperature nitrogen at up to $5 \mathrm{lbm} . / \mathrm{sec}$. at $1000 \mathrm{psig}$ and water at up to $150 \mathrm{gpm}$ at 500 psig are currently available. Hydrogen will be plumbed to the test chamber during the modification. Ambient temperature hydrogen will be available at up to $3.7 \mathrm{lbm} . / \mathrm{sec}$. While hydrogen run through a liquid nitrogen heat exchanger to reduce its temperature to about $220^{\circ} \mathrm{R}$ will be available at up to $1.4 \mathrm{lbm}$. $/ \mathrm{sec}$, both at 1000 psig. The locai storage capacity for hydrogen will be sufficient to support 3 runs of $90 \mathrm{sec}$. duration at the maximum flow rate of $5.1 \mathrm{lbm} / \mathrm{sec}$. While there will be controls for all of these fluids, the detailed control system for use with a given model will have to be provided as part of the model hardware. Also shown on the figure are fluids which are available nearby but not in the test chamber. The use of any of these fluids would require the additional plumbing and contols necessary to get them into the test chamber and control their use therein.

Data Acquisition and Reduction. There are current Ty 288 channels of instrumentation available in the test chamber (192 channels for strain gage type instrumentation and 96 channe is for thermocouples). The current system is controlled by a Xerox 530 minicomputer. As part of the modification a new data acquisition and reduction system will be installed. This new system is detailed on figure 21. A new Neff Mode 1600 ana log front end will be interfaced with a Modcomp $32 / 8532$ bit minicomputer for data acquisition and real time display. The Neff will have the capability of handling up to 512 channels of analog data with se lectable ranges of from $+/-5$ millivolts up to $+/-10.24$ volts. The Neff will output a digital 16 bit result which is accurate to $+1-0.02 \%$.

The normal scan rate for the 512 channels will be $50 \mathrm{frames} / \mathrm{sec}$. However, up to 80 of these channels can be configured to scan at the rate of 5000 frames/sec. for up to a minimum of 100 millisec., and up to 10 additional channe 1 s can be scanned by a separate transient data recorder at the rate of 500,000

frames/sec. for up to a minimum of 10

millisec. The number of channels/recording time for the medium and high speed data channels is storage limited by disc space on the Modcomp and memory space in the transient data recorder. That is, additional scan time at the high rates can be obtained by reducing the number of channels scanned at the high rates. In addition to controlling the Neff and storing the raw digital data, the Modcomp will also provide real time data reduction capability for display of up to 24 pages of 23 data items per page of either raw channel data, engineering units, or a few 
calculated quantities such as Mach number updated at the rate of 4 times per sec. Although it is anticipated that due to the short run time only 1 or 2 pages will be actually displayed during a run, the others will be stored for display after the run has been completed. Additionally, there will be the capability to graphically display up to 40 data channels in a 4 window graphics display terminal. The channel data may be plotted against another channel or against time. Again, it is anticipated that only 1 or 2 of these pages will be displayed during the run and the others will be available after the run. once the data have been acquired they will be transferred after the run to a data reduction host processor consisting of 2 Digital Equipment Corp. VAX 32 bit computers (Mode 158530 and 8550 ). The vaxes will then be used for final data reduction lengineering units, heating rates, Fourier transforms, statistical analyis, etc.). There will a iso be the capability to generate data analys is plots, print-outs, data tapes for transmittal, and whatever other necessary computations are desired including accomodations for user generated software.

Schedule. - Figure 22 presents a current schedule for the modification project. The detailed design of the facility modification was completed by Fluidyne Engineering in 1985. An independent contract for design and fabrication of the transpiration cooled, $M$ $=7$ nozzle was awarded to Aerojet Tech Systems in 1985. The final aerodynamic lines were forwarded to them in early 1987. The Modcomp/Neff data acquisition system has been procured and is currently in the installation process. The 2 data reduction host VAX computers will be procured one in this fiscal year and the other next fiscal year while the host software is under development. A contract for the major constrution part of the project was awarded to Chicago Bridge and Iron (CBI-NACON) in mid 1986. The construction phase is scheduled for 29 months with the facility down for a period of 9 months for installation of the modifications beginning in June, 1988. Construction will be followed by a planned period of about a year for facility shakedown and calibration. The facility should be available for research in early 1990.

\section{CONCLUDING REMARKS}

This paper has described the currently underway modifications to the NASA Langley Research Center 8-Foot High Temperature Tunnel which will result in a unique national facility for the investigation of high Mach number propulsion systems, aerothermal loads, and aerotherma 1 structures. The facility is being modified with the addition of a LOX system to bring the oxygen content of the high enthalpy test medium up to that of air, modified nozzles to enable the tunnel to operate at the additional Mach numbers of 4 and 5 , the addition of hydrogen plumbing to the test chamber to allow the testing of hydrogen powered engines, and a new data system to increase both the amount of data that may be obtained and the efficiency of its acquisition and reduction. When the modifications are complete the nation's propulsion test capability will be extended to $M=7$ for large mode is with operating engines. Covered will be the very critical transition Mach number ranges for both turbojet to ramjet transition and ramjet to scramjet transition as we 11 as Mach numbers for both ramjet and scramjet operation. In addition, the test capability for

determination of aerothermal loads and evaluation of aerothermal structures for large test specimens will be extended to the additional Mach numbers of 4 and 5 . It is anticipated that the modified tunne 1 will come on-line in time to provide significant research support to the development of propulsion systems for the upcoming generation of hypersonic vehicles.

\section{REFERENCES}

1. Williams, Robert M.: National AeroSpace Plane: Technology for America's Future. Aerospace America, November, 1986, pp. 18-22.

2. Kelly, H. N. and Wieting, A. R.: Modification of NASA Langley 8-Foot High Temperature Tunne 1 To Provide a Unique National Research Facility for Hypersonic Air-Breathing Propulsion Systems. NASA TM 85783, May, 1984.

3. Staff of the Langley Research Center and AiResearch Manufacturing Co., The Garrett Corp.: Hypersonic Research Engine Project Technological Status 1971. NASA TM X-2572, September, 1972.

4. Howe 11, R. R. and Hunt, L. R.: Methane-Air Combustion Gases as an Aerodynamic Test Medium. Journal of Spacecraft and Rockets, Vol. 9, No. 1, pp. 7-12, January, 1972.

5. Rogers, R. Clayton and Schexnayder, Charles J.: Chemical Kinetic Analys is of Hydrogen-Air Ignition and Reaction Times. NASA TP 1856, July, 1981.

6. Rogers, R. Clayton: Effects of Test Facility Contaminants on Supersonic Hydrogen-A ir Diffusion Flames. Presented at the 23rd JANNAF Combustion Meeting, Hampton ,VA, October 20-24, 1986. 
7. Singh, Jag J.; Davis, William T.; and Puster, Richard L.: Proposed Fast-Response Oxygen Monitoring and Control System for the Langley 8-Foot High-Temperature Tunne1. NASA TP 2218 , November, 1983.

8. Vaoller, H. W.: Performance of a Transpiration-Regenerative Cooled Rocket Thrust Chamber. NASA CR 159742, September, 1979.

9. Trimble, M. H.; Smith, R. T.; and Mathews, R. K.: AEDC High-Temperature Testing Capabilities. AEDC-TR-78-3, Apri1, 1978.

10. Thomas, Scott R, and Guy, Robert W.: Expanded Operational Capabilities of the Langley Mach 7 Scramjet Test Facility. NASA TP 2186, October, 1983.

11. Carter, P. B. and Turrentine, W. A.: Investigation of Flow Dynamics in a B lowdown Type Propuls ion Wind Tunnel. AIAA Paper No. 77-990, July, 1977.

12. Er lebacher, Gordon; Kumar, Ajay; Anderson, E. Clay; Rogers, R. Clayton; Salas, Manue 1 D.; Harris, Julius E.; and Dwoyer, Douglas L.: A Computational Design Procedure for Actively Cooled Hypersonic Wind-Tunnel Nozzles Subject to Wall Shape Constraints. Presented at the CFO in Aerospace Design Workshop at the University of Tennessee Space Institute, Tullahoma, Tennessee, June 4-6, 1985 .

13. Kumar, Ajay: Numerical Analys is of the Scramjet-In let Flow Field by Using Two-Dimensional Navier-Stokes Equations. NASA TP 1940, 1981.

14. Kumar, Ajay: User's Guide for NASCRIN - A Vectorized Code for Calculating Two-Dimensional Supersonic Internal flow Fields. NASA TM 85708, February, 1984.

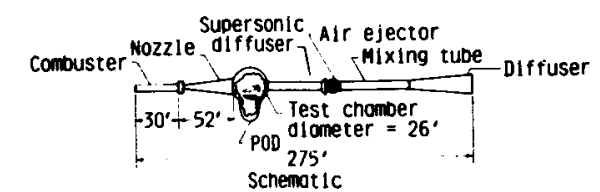

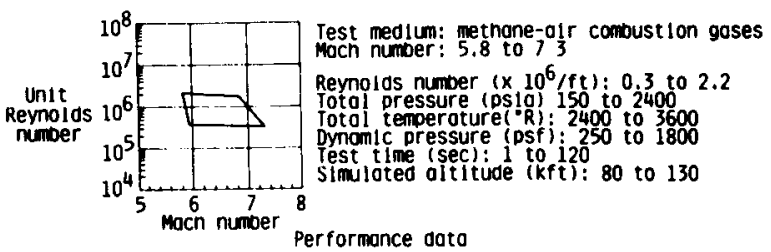

Figure 1.- Schematic and operational characteristics of the Langley 8-Foot High Temperature Tunne 1.

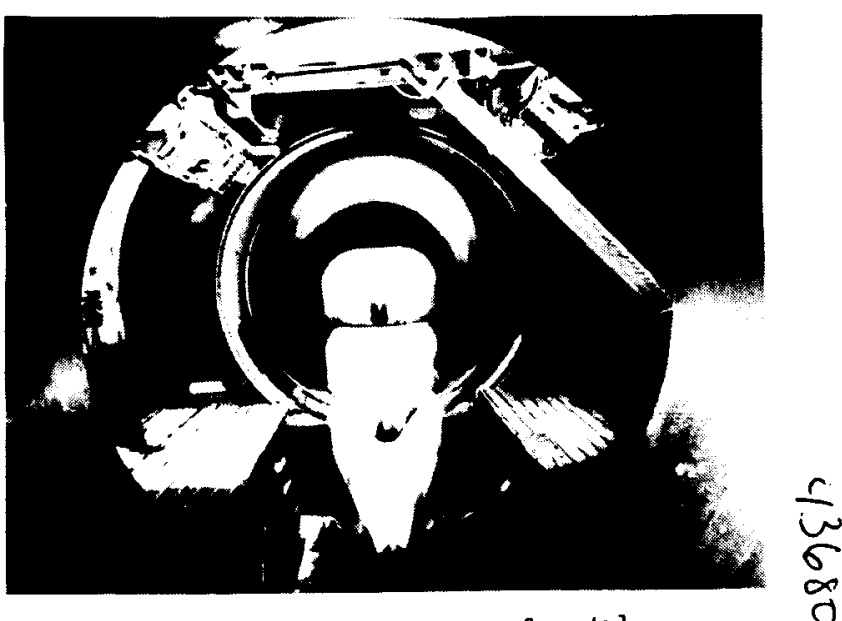

Figure 2.- Iriple exposure of mode 1 entering 8-Foot High Temperature Tunnel Test Section.

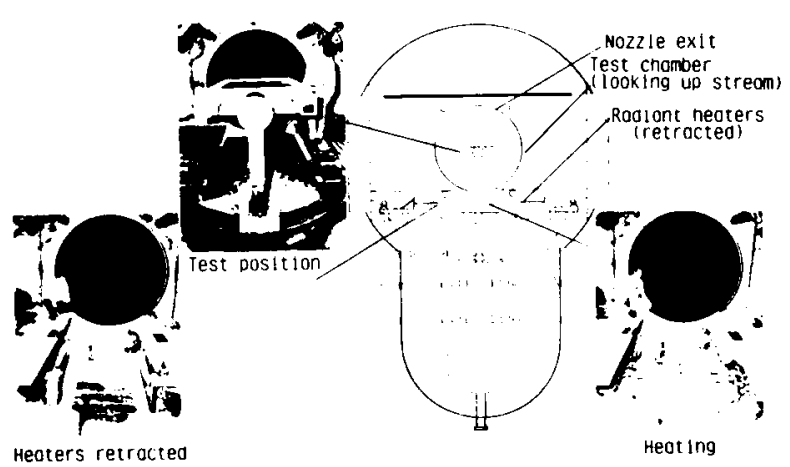

Figure 3.- 8-Foot High Temperature Tunne 1 radiant preheating apparatus.

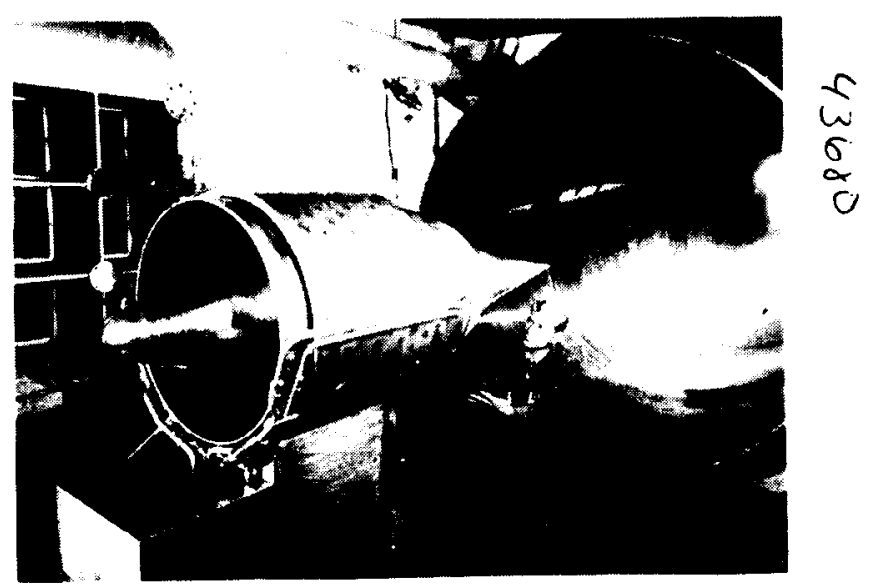

Figure 4.- Structural assemb ly model (SAM) of the hypersonic research engine (HRE) in the 8-Foot High Temperature Tunnel. 


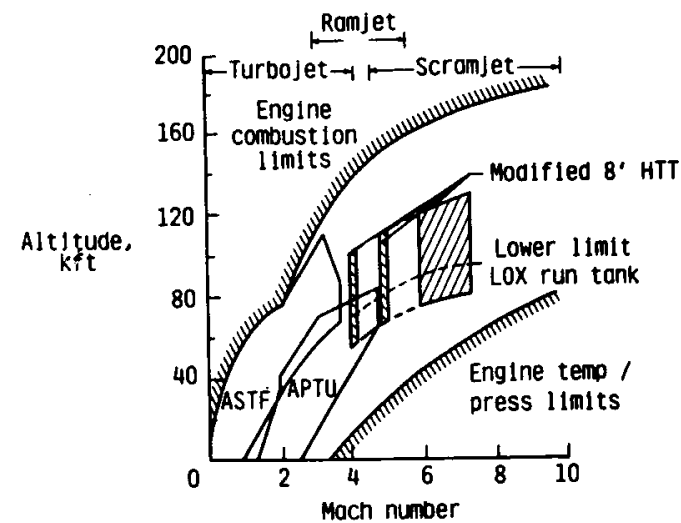

Figure 5.- Operational envelopes for air-breathing engines and propulsion facilities.

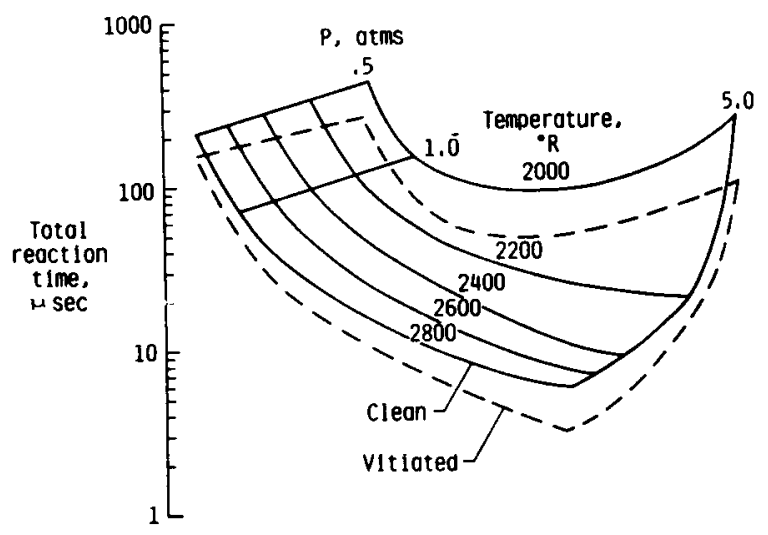

Figure 6.- Calculated reaction times for hydrogen in clean and vitiated air.

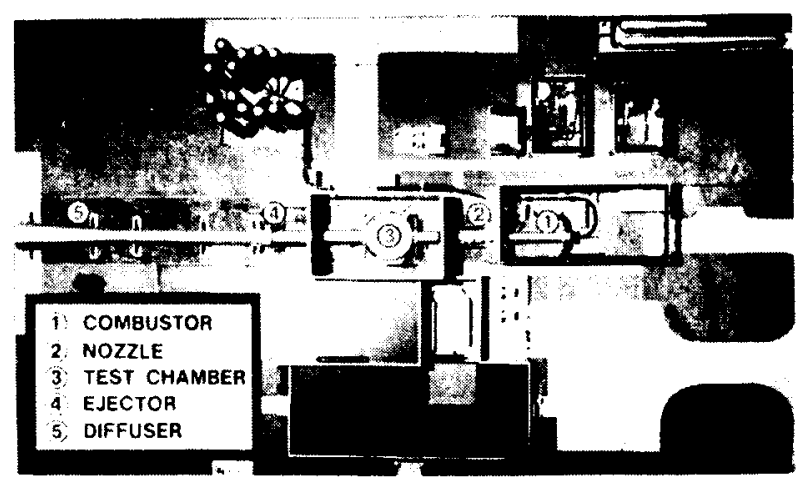

Figure 7.- Layout of 8-Foot High Temperature Tunnel.

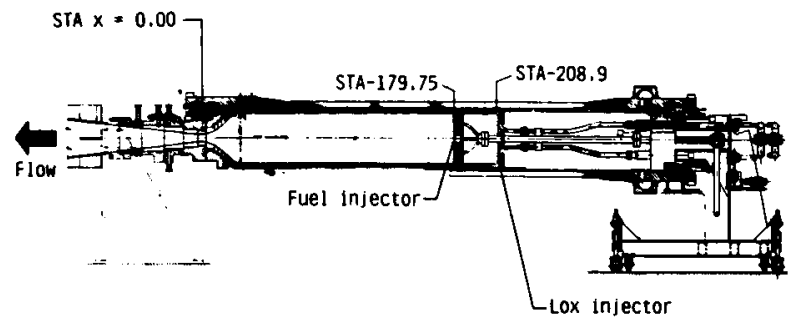

Figure 8. - Cross Section of 8-Foot High Temperature Tunnel Combustor.

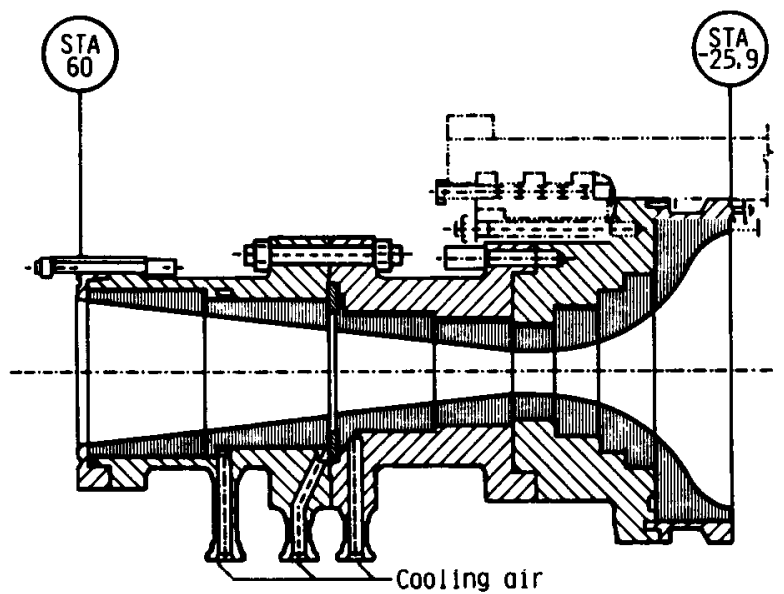

Figure 9.- Transpiration cooled approach section and throat.

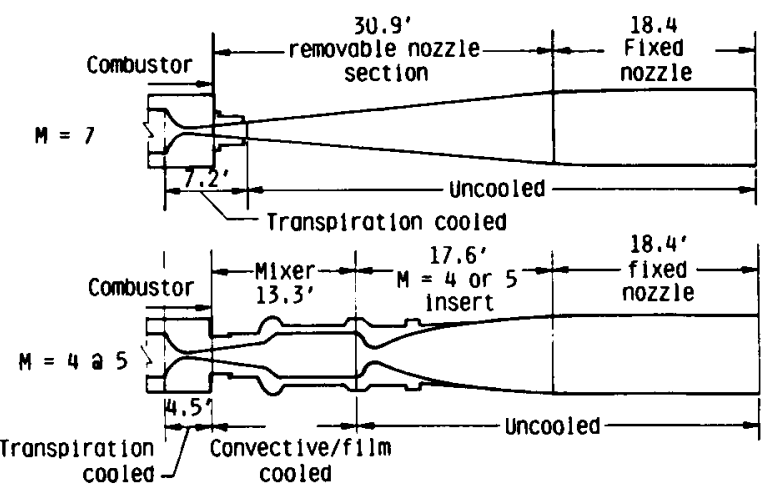

Figure 10.- Modified nozzles for alternate Mach number capability. 


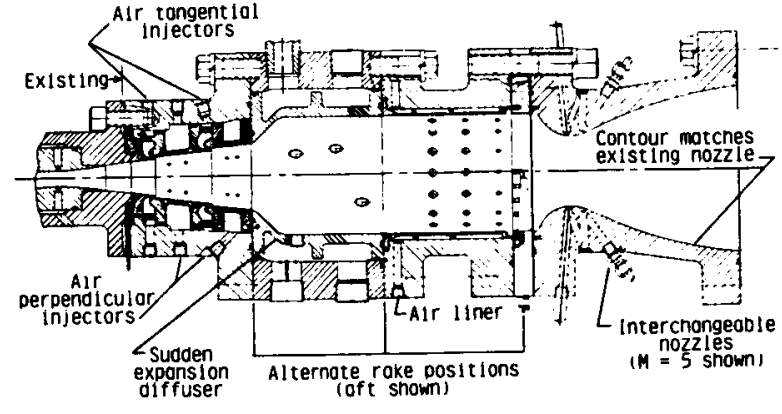

Figure 11.- Successful pilot tunnel mixer design.

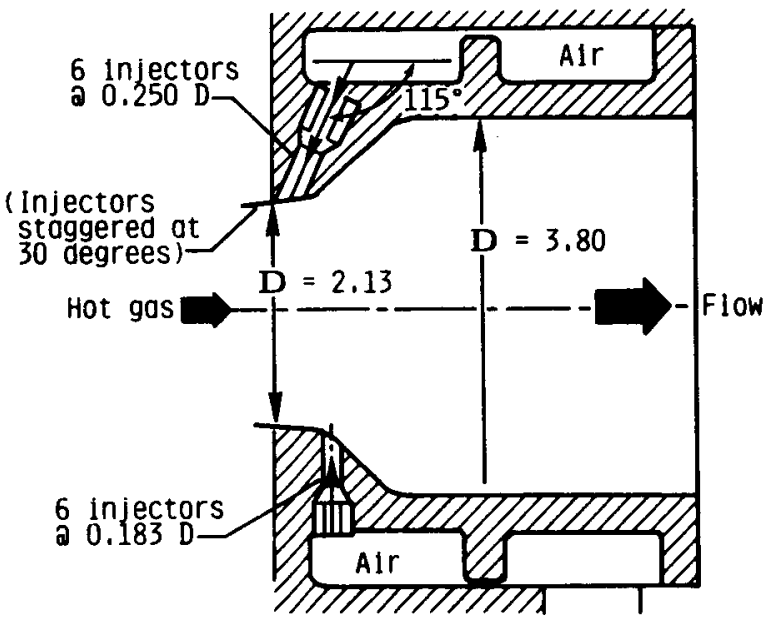

Figure 12.- Main air injectors for pilot tunnel mixer.

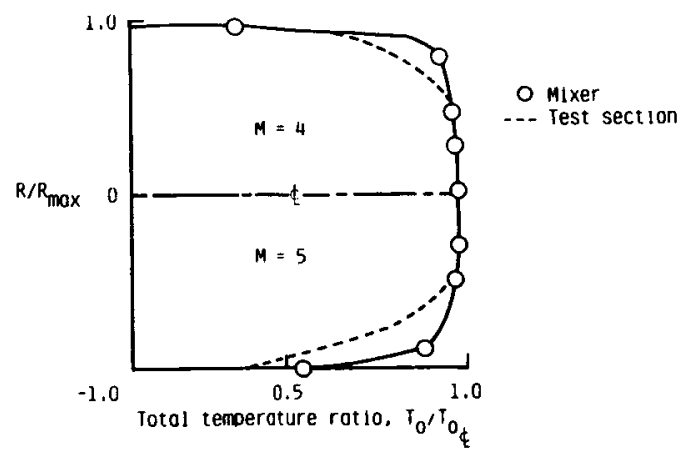

Figure 13.- Total temperature profiles in pilot tunnel mixer and test section for $M$ $=4$ and 5 .

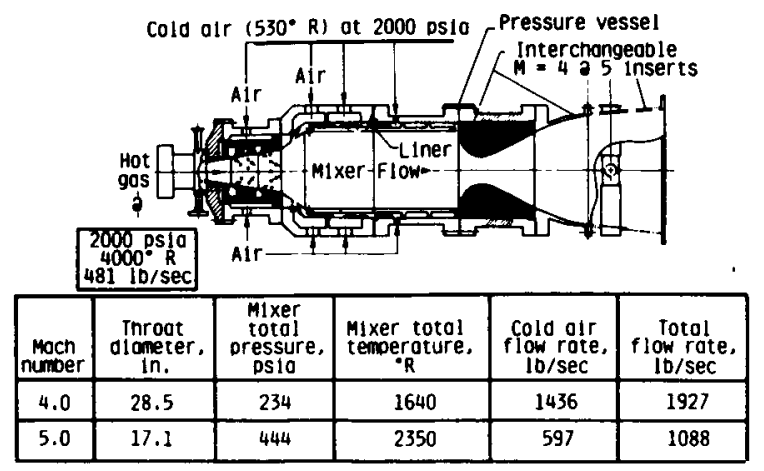

Figure 14.- Mixer design for 8-Foot High Temperature Tunnel.

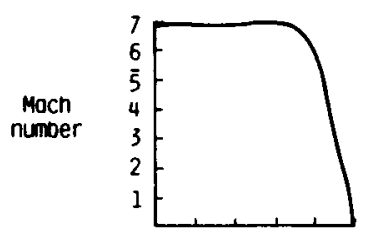

$$
M=7,5,4
$$

$0 \quad 10 \quad 20 \quad 30 \quad 40 \quad 50$
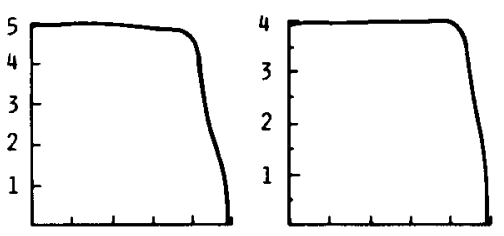

Tunnel radius, in

Figure 15.- Predicted exit-plane Mach number contours.

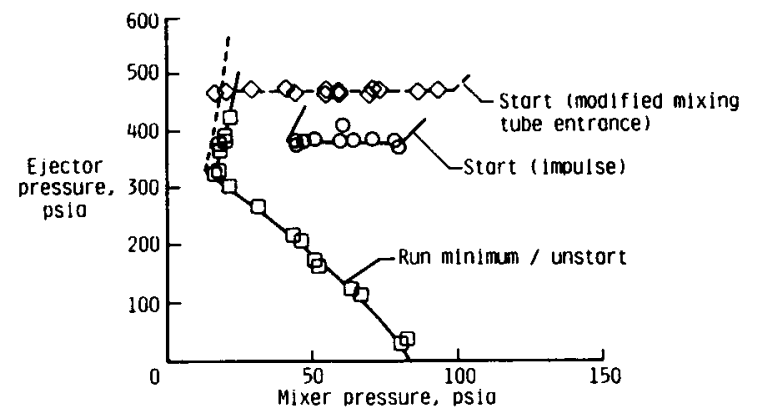

Figure 16.- Starting and running operational pressure boundaries for the pi lot tunnel at $M=4$. 


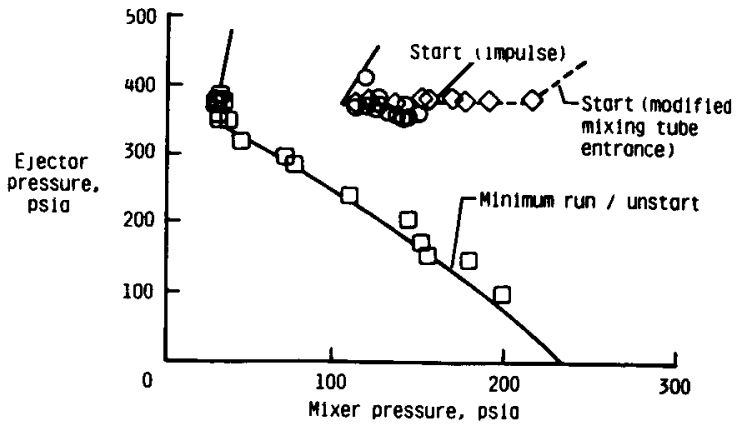

Figure 17.- Starting and running operational pressure boundaries for the pilot tunnel at $M=5$.

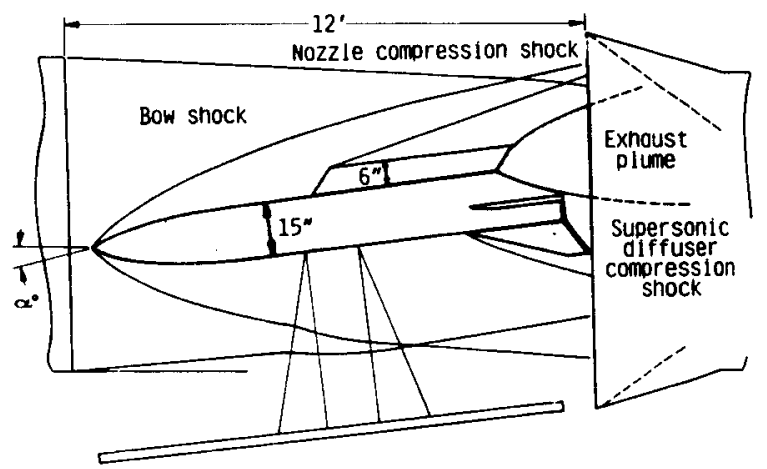

Figure 18.- Typical large model of an airbreathing missile mounted in the 8-Foot High Temperature Tunnel test chamber.

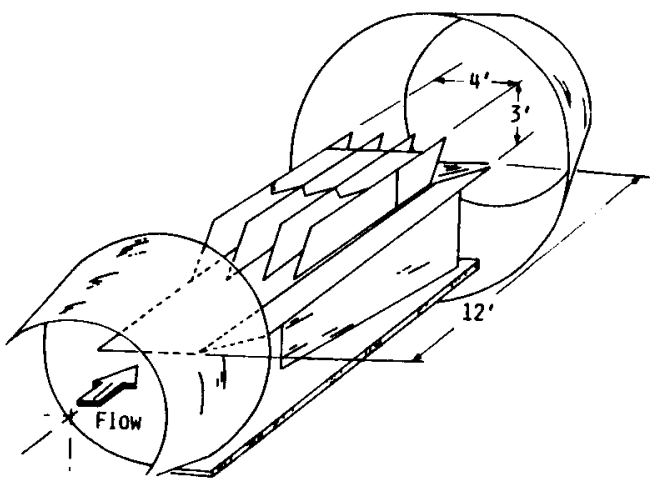

Figure 19.- Concept of multiple scramjet engine module mounted in the 8-Foot ligh Temperature Tunnel test chander.
In test chamber

Power-1.6 MW a 440 volts controlled

Fluids $-H_{2}-3.71 \mathrm{dm} / \mathrm{sec}$ a $540^{\circ} \mathrm{R} \& 1000 \mathrm{Dsig}$ $-1.4 \mathrm{~lm} / \mathrm{sec}$ a $220^{\circ} \mathrm{R} \& 1000 \mathrm{psig}$ $\mathrm{N}_{2}-5 \mathrm{lDm} / \mathrm{sec}$ a $540^{\circ} \mathrm{R} \& 1000 \mathrm{psig}$

Nearby $\mathrm{H}_{2} \mathrm{O}^{-150 \mathrm{gom}}$ a $540^{\circ} \mathrm{R} \& 500 \mathrm{psig}$

6000 psi oir

$6000 \mathrm{psi} \mathrm{N}_{2}$

LOX

$\mathrm{LN}_{2}$

$\mathrm{H}_{2}{ }^{0}-1200$ gpm 2500 psig

Figure 20.- Utilities to be available in or near the 8-Foot High Temperature Tunnel test chamber.

Doto system (MODCOMP $32 / 85$ with MEFF 600)

- $5 m v-10.24 v,+.02 x$ occuracy-16 bits

- 512 channels a 50 frames/sec

- 80 channels a 5000 frames/sec for $100 \mathrm{~ms}$

- 10 chonnels a 500,000 frames/sec for $10 \mathrm{~ms}$

- 552 dota items real time alpho numeric alsploy

- 40 dota items real time grophic display

Host doto processor (VAX 8530 ond VAX 8550)

- 32 DIt-10 mFLOP cluster

- Timely post run analysis

(engineering units, heating rotes, fast fourier tronsforms, etc

Figure 21.- Upgraded data acquisition and reduction systems for the 8-Foot High

Temperature Tunnel.

\begin{tabular}{|c|c|c|c|c|c|c|}
\hline Activity & CY85 & CY86 & CY 87 & CY88 & CY89 & CY90 \\
\hline \multicolumn{7}{|l|}{ Final design } \\
\hline \multicolumn{7}{|l|}{$\begin{array}{l}\text { Transpiration cooled } \\
\text { nozzle }\end{array}$} \\
\hline \multicolumn{7}{|l|}{ Major construction } \\
\hline \multicolumn{7}{|l|}{ Data oquisition system } \\
\hline \multicolumn{7}{|l|}{ Host computer } \\
\hline Cneckout and calibration & & & & & & \\
\hline Research tests & & & & & & \\
\hline
\end{tabular}

Figure 22.- 8-Foot High Temperature Tunnel modification schedule. 
Standard Bibliographic Page

\begin{tabular}{|c|c|c|c|}
\hline $\begin{array}{l}\text { 1. Report No. } \\
\text { NASA TM-100486 }\end{array}$ & 2. Government Accession No. & \multicolumn{2}{|c|}{ 3. Recipient's Catalog No. } \\
\hline \multirow{2}{*}{\multicolumn{2}{|c|}{$\begin{array}{l}\text { 4. Title and Subtitle } \\
\text { Mbdification to the Langley \&-Foot High Temperature } \\
\text { Tunnel for Hypersonic Propulsion Testing }\end{array}$}} & \multicolumn{2}{|l|}{$\begin{array}{l}\text { 5. Report Date } \\
\text { June } 1987\end{array}$} \\
\hline & & \multicolumn{2}{|c|}{ 6. Performing Organization Code } \\
\hline \multicolumn{2}{|c|}{$\begin{array}{l}\text { 7. Author(s) } \\
\text { D. E. Reubush, R. L. Puster, H. N. Kelly }\end{array}$} & \multicolumn{2}{|c|}{ 8. Performing Organization Report No. } \\
\hline \multirow{2}{*}{\multicolumn{2}{|c|}{$\begin{array}{l}\text { 9. Performing Organization Name and Address } \\
\text { NASA Langley Research Center } \\
\text { Hampton, VA 23665-5225 }\end{array}$}} & \multicolumn{2}{|c|}{$\begin{array}{l}\text { 10. Work Unit No. } \\
506-41-21-01\end{array}$} \\
\hline & & \multicolumn{2}{|c|}{ 11. Contract or Grant No. } \\
\hline \multirow{2}{*}{\multicolumn{2}{|c|}{$\begin{array}{l}\text { 12. Sponsoring Agency Name and Address } \\
\text { National Aeronautics and Space Administration } \\
\text { Washington, DC } 20546-0001\end{array}$}} & \multicolumn{2}{|c|}{$\begin{array}{l}\text { 13. Type of Report and Period Covered } \\
\text { Technical Memorandum }\end{array}$} \\
\hline & & \multicolumn{2}{|c|}{ 14. Sponsoring Agency Code } \\
\hline \multicolumn{4}{|c|}{$\begin{array}{l}\text { 15. Supplementary Notes } \\
\text { Presented at AIAA/SAE/ASME 23rd JOINT PROPULSION CONFERENCE in San Diego, CA, } \\
\text { on June } 29 \text { - July 2, 1987. AIAA Paper No. } 87-1887 \\
\text { D. E. Reubush and R. L. Puster, Langley Research Center, Hampton, Virginia. } \\
\text { H. N. Kelly, PRC Kentron, Hampton, Virginia. }\end{array}$} \\
\hline \multicolumn{4}{|c|}{$\begin{array}{l}\text { 16. Abstract } \\
\text { This paper describes the modifications currently underway to the Langley } \\
\text { 8-Foot High Temperature Tunnel to produce a new, unique national resource for } \\
\text { testing of hypersonic air-breathing propulsion systems. The current tunnel, } \\
\text { which has been used for aerothermal loads and structures research since its } \\
\text { inception, is being modified with the addition of a Lox system to bring the } \\
\text { oxygen content of the test medium up to that of air, the addition of alternate } \\
\text { Mach number capability ( } 4 \text { and } 5) \text { to augment the current } M=7 \text { capability, } \\
\text { improvements to the tunnel hardware to reduce maintenance downtime, the addition } \\
\text { of a hydrogen system to allow the testing of hydrogen powered engines, and a } \\
\text { new data system to increase both the quantity and quality of the data obtained. } \\
\text { The paper discusses both the modifications and the development thereof. }\end{array}$} \\
\hline $\begin{array}{l}\text { 17. Key Words (Suggested by Authors(s)) } \\
\text { Hypersonic Wind Tunnel } \\
\text { Hypersonic Propulsion Testing } \\
\text { Ground Testing } \\
\text { Vitated Test Medium }\end{array}$ & $\begin{array}{l}\text { 18. Distribution Stat } \\
\text { Unclass ifie } \\
\text { Subject Cat }\end{array}$ & $\begin{array}{l}\text { ment } \\
\text { gory }-34\end{array}$ & \\
\hline $\begin{array}{l}\text { 19. Security Classif.(of this report) } \\
\text { Unclass ified }\end{array}$ & $\begin{array}{l}\text { 20. Security Classif.(of this page) } \\
\text { Unclass ified }\end{array}$ & \begin{tabular}{|c|} 
21. No. of Pages \\
12
\end{tabular} & $\begin{array}{l}\text { 22. Price } \\
\mathrm{A} 02\end{array}$ \\
\hline
\end{tabular}

For sale by the National Technical Information Service, Springfield, Virginia 22161

NASA Langley Form 63 (June 1985) 